\title{
Emissions and ambient distributions of Biogenic Volatile Organic Compounds (BVOC) in a ponderosa pine ecosystem: interpretation of PTR-MS mass spectra
}

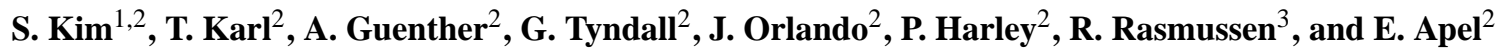 \\ ${ }^{1}$ Advanced Study Program, National Center for Atmospheric Research Boulder, CO, USA \\ ${ }^{2}$ Atmospheric Chemistry Division, National Center for Atmospheric Research, Boulder, CO, USA \\ ${ }^{3}$ Oregon Graduate Institute, Beaverton, OR, USA
}

Received: 3 September 2009 - Published in Atmos. Chem. Phys. Discuss.: 2 October 2009

Revised: 14 January 2010 - Accepted: 28 January 2010 - Published: 16 February 2010

\begin{abstract}
Two proton-transfer-reaction mass spectrometry systems were deployed at the Bio-hydro-atmosphere interactions of Energy, Aerosols, Carbon, $\mathrm{H}_{2} \mathrm{O}$, Organics and Nitrogen-Southern Rocky Mountain 2008 field campaign (BEACHON-SRM08; July to September, 2008) at the Manitou Forest Observatory in a ponderosa pine woodland near Woodland Park, Colorado USA. The two PTR-MS systems simultaneously measured BVOC emissions and ambient distributions of their oxidation products. Here, we present mass spectral analysis in a wide range of masses $\left(\mathrm{m} / \mathrm{z}, 40^{+}\right.$to $\left.210^{+}\right)$ to assess our understanding of BVOC emissions and their photochemical processing inside of the forest canopy. The biogenic terpenoids, 2-methyl-3-butene-2-ol (MBO, 50.2\%) and several monoterpenes (MT, 33.5\%) were identified as the dominant BVOC emissions from a transmission corrected mass spectrum (PTR-MS), averaged over the daytime (11 a.m. to 3 p.m., local time) of three days. To assess contributions of oxidation products of local BVOC, we calculate an oxidation product spectrum with the $\mathrm{OH}$ - and ozone-initiated oxidation product distribution mass spectra of two major BVOC emissions at the ecosystem (MBO and $\beta$-pinene) that were observed from laboratory oxidation experiments. The majority $(\sim 76 \%)$ of the total signal in the transmission corrected PTR-MS spectra could be explained by identified compounds. The remainder are attributed to oxidation products of BVOC emitted from nearby ecosystems and transported to the site, and oxidation products of unidentified BVOC emitted from the ponderosa pine ecosystem.
\end{abstract}

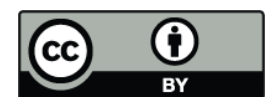

Correspondence to: S. Kim

(saewung@ucar.edu)

\section{Introduction}

Emissions and oxidation processes of biogenic volatile organic compounds (BVOC) in the troposphere have been intensively studied for several decades (Wiedinmyer et al., 2004; Guenther et al., 1995; Fuentes et al., 2000; Andreae and Crutzen, 1997). These studies indicate that global biogenic VOC emissions $(\sim 1150 \mathrm{Tg}$ C/year; Guenther et al., $1995)$ are an order of magnitude higher than anthropogenic emissions ( $\sim 160 \mathrm{Tg}$ C/year; Benkovitz et al., 2004). Their oxidation processes directly affect local and global air quality. For example, Ryerson et al. (2001) found that reactive BVOC (e.g., isoprene) are an important factor controlling ozone formation downwind of power plant plumes in the southeastern US. Kanakidou et al. (2005) reviewed the importance of BVOC for processes influencing the formation of secondary organic aerosol and cloud condensation nuclei, which have significant implications for global climate (IPCC 2007). In addition, Guenther (2002) and Kesselmeier et al. (2002) concluded that reactive BVOC have significant implications for the global carbon cycle.

Our understanding of BVOC emissions and photochemistry has significantly improved in the past decade (e.g. Guenther et al., 2006 and Atkinson and Arey, 2003) yet a number of recent laboratory and field studies indicate that significant issues related to unexplored BVOC or their oxygenated products remain unsolved. For example, Zhao et al. (2004) reported a high yield $(\sim 30 \%)$ of $\mathrm{C} 4$ and C5 carbonyl compounds from the oxidation of isoprene $\left(\mathrm{C}_{5} \mathrm{H}_{8}\right)$, yet these species have not been measured in ambient air due to technical difficulties (Goldstein and Galbally, 2007). A field study in a ponderosa pine forest canopy (Lee et al., 2005) reported that total monoterpene (MT)

Published by Copernicus Publications on behalf of the European Geosciences Union. 
concentrations, measured by proton transfer reaction-mass spectrometry (PTR-MS) were consistently higher $(\sim 30 \%)$ than sums of the speciated MT concentrations, measured by the gas chromatography method. The investigators suggest that this difference indicates that substantial amounts of reactive MT are not detected by conventional Gas Chromatography (GC) analytical methods. Indeed, significant missing OH reactivity (Di Carlo et al., 2004) and unexpected chemical ozone loss (Kurpius and Goldstein, 2003), reported inside of forest canopies, suggest that undetected BVOC could have important implications for photochemistry.

Here we present a detailed mass spectral analysis $\left(\mathrm{m} / \mathrm{z}=40^{+}\right.$to $\left.210^{+}\right)$of BVOC emissions using PTR-MS and GC-MS. We compare branch enclosure BVOC emission measurements with ambient VOC distributions in a ponderosa pine forest. The universal sensitivity of PTR-MS for most VOC exhibiting a proton affinity greater than water provided a capability to examine unidentified BVOC. In addition, complementary measurements were made by GC-MS techniques. Recent work on quantifying the impact of mass discrimination characteristics of the PTR-MS system (from $m / z 40^{+}$to $m / z 210^{+}$; e.g. Kim et al., 2009 and Taipale et al., 2008) provide new constraints for quantification of unidentified BVOC and their oxidation products in the higher molecular weight mass range (e.g. $>100 \mathrm{amu}$ ). Using these constraints, we compare the observed ambient spectra of forest air with the laboratory observed $\mathrm{OH}$ and ozone initiated oxidation product mass spectra of two major BVOC emissions in the ecosystem, 2-methyl-3-butene-2-ol (MBO) and $\beta$-pinene. Our analysis examines the main uncertainties associated with sources of missing organic carbon in forest environments (e.g., primary production of BVOC vs. photochemical production) (Di Carlo et al., 2004, Lou et al., 2009; and Holzinger et al., 2005).

\section{Methods}

\subsection{Site}

The field study was conducted at the Manitou Forest Observatory (MFO, https://wiki.ucar.edu/display/mfo/Manitou+ Forest+Observatory) from 21 July to 19 September 2008. The MFO is located in the Manitou Experimental Forest (elevation $2286 \mathrm{~m}$, latitude $39^{\circ} 6^{\prime} 0^{\prime \prime}$, and longitude $105^{\circ} 5^{\prime} 30^{\prime \prime}$ ), maintained by the US Forest Service. The site is representative of the Central Rocky Mountains ponderosa pine zone. Year long trace gas monitoring at the site (Smith et al., in preparation) indicates that relatively clean air masses from the southwest predominate and anthropogenic pollution plumes from nearby cities such as Colorado Springs and Denver were rarely transported to the site.

\subsection{Branch enclosure system}

A $5 \mathrm{~L}$ Teflon bag with two $1 / 4^{\prime \prime}$ Teflon tube fittings (Welch Fluorocarbon, Dover, $\mathrm{NH}$ ) enclosed a ponderosa pine branch with mature needles that was located approximately four meters above the ground. Ambient air was pumped through a charcoal scrubber to remove VOC and ozone and then introduced into the enclosure at a rate of $\sim 2.5 \mathrm{slm}$ (standard liter per minute). VOC concentrations in the scrubbed air entering the enclosure were measured once every hour for background subtractions. Mass spectra obtained by PTR-MS during the night when BVOC emissions were significantly lower than those during the day indicated that there was no significant background interference with the BVOC emission measurements. Air temperature inside the enclosure was measured using a K-type thermocouple and logged on a computer. We found that BVOC emissions were always higher during the first day following installation of the enclosure. To avoid BVOC artifacts due to mechanical disturbance during installation, data collected during the first day after the installation were therefore excluded. Measurements of BVOC emissions were conducted for four full days after emissions had stabilized. After each measurement period, the enclosure was opened, exposing the branch to ambient conditions for 2 days before enclosing it again for subsequent measurements. At the conclusion of the experiment, the branch was harvested, and needles were dried at $70^{\circ} \mathrm{C}$ for $\sim 48 \mathrm{~h}$ and weighed.

\subsection{PTR-MS and GC-MS}

Two high sensitivity PTR-MS systems (IONICON Analytik, Innsbruck Austria) were deployed during the field campaign. General information for the analytical technique can be found in Blake et al. (2009) and references therein. Kim et al. (2009) and Karl et al. (2005) presented information on the analytical characteristics and calibration procedures for the specific instruments used in this study. Since we explore a wide range of molecular masses $\left(m / z=40^{+}\right.$to $\left.210^{+}\right)$, the mass discrimination of the system was carefully characterized before and after the field campaign with a certified standard gas (Matheson Tri Gas, USA) containing 14 aromatic compounds from benzene (MW 78) to trichlorobenzene (MW 180). The relative sensitivity over the mass range generally declines in an exponential function. In addition, we calibrated relative sensitivities at $m / z 205^{+}$, the molecular weight of the protonated sesquiterpene (SQT) parent ion with a triisopropylbenzene standard generated by a capillary diffusion system (CDS) located at the University of Colorado at Boulder (Helmig et al., 2004). The experiment demonstrated that the exponential fitting line, based on the certified aromatic standards, predicts the transmission efficiency reasonably well (Kim et al., 2009). The average deviation from the transmission curve is estimated to be $\sim 15 \%$, an error very similar to the estimation of Taipale et al. (2008). 
Branch enclosure and ambient air samples were also analyzed using GC-MS methods. In situ measurements were made at the field site using a portable GC-MS with an internal microtrap concentrator and a $30 \mathrm{~m} \times 0.32 \mathrm{~mm}$ ID $1 \mathrm{~mm}$ film DB-1 column, temperature programmed from $40^{\circ} \mathrm{C}$ to $200^{\circ} \mathrm{C}$ (Hapsite Smart, INFICON, East Syracuse, NY, USA). Air from the enclosure was directly routed to the portable GC-MS to collect $1 \mathrm{~L}$ samples on the microtrap and used for quantitative speciation of MBO, and the dominant MT, oxygenated-MT and qualitative speciation of SQT. Higher volume branch enclosure and ambient air samples $(6 \mathrm{~L})$ were collected onto stainless steel two-stage sorbent tubes filled with Tenax and Carbotrap, and then thermally desorbed and analyzed with the portable GC-MS. An ozone trap (LpDNPH ozone scrubber (KI), Supelco USA) was used on the ambient air-sampling inlet. To examine tree-to-tree variations of BVOC emission, leaf cuvette samples with Tenax/Carbotrap sorbent tubes were also analyzed using a GC-flame ionization detector (FID). Additionally, diurnal variations of ambient BVOC were measured by collecting air in stainless steel canisters ( $2 \mathrm{~L}$ ), which were subsequently analyzed by an Agilent GC-MS in laboratories in Boulder, $\mathrm{CO}$ and Portland, OR.

\subsection{Environmental chamber}

After the field campaign, we conducted laboratory oxidation experiments on two of the major BVOC species (MBO, $\beta$ pinene) observed at the Manitou forest site using a stainless steel environmental chamber (Shetter et al., 1987), $2 \mathrm{~m}$ in length with a volume of $47 \mathrm{~L}$. For each oxidation experiment, the concentrations of reactants and products were monitored by both a Bomem DA3.01 Fourier transform infrared spectrometer with scan range of $800-3900 \mathrm{~cm}^{-1}$ and the PTRMS system, monitoring oxidation products from each experiment for the same mass range of the field measurement $\left(\mathrm{m} / \mathrm{z} 40^{+}-210^{+}\right)$. The experimental details of $\mathrm{OH}$ and ozoneinitiated experiments can be found in Orlando et al. (2000). $\mathrm{OH}$ was generated by photolysis of organic nitrite (i-butyl nitrate) in the presence of NO. Aliqouts of ozone were added every 10 to $15 \mathrm{~min}$ until at least $\sim 70 \%$ of reactants had reacted. Typical experiments were conducted in the time span of 20 to $30 \mathrm{~min}$ to minimize possible wall losses. We simulated high $\mathrm{NO}$ environments for the chamber experiments so that we can compare oxidation products of BVOC at MFO which is usually in the high $\mathrm{NO}$ regime $(\mathrm{NO}>100 \mathrm{pptv})$.

\section{Results}

\subsection{Fragmentation patterns}

For accurate interpretations of mass spectra, it is essential to have a comprehensive understanding of the fragmentation patterns of analyte ions. Fragmentation patterns of various compounds have been extensively investigated with different reagent ion systems and chemical ionization has been clearly shown to result in less pronounced fragmentation than electron impact ionization (Harrison, 1992). A number of studies using PTR-MS have reported fragmentation patterns of BVOC (e.g. Kim et al., 2009 and Tani et al., 2003). In this section, we summarize fragmentation patterns of BVOC groups for the $\mathrm{H}_{3} \mathrm{O}^{+}$reagent ion system based on their functional groups. We focus here on BVOC relevant to this study, and refer to other references (de Gouw and Warneke, 2007) for other VOC.

In the Brønsted acid chemical ionization reagent system, the larger differences in proton affinity between the analyte and the conjugate base of the reagent ion cause more pronounced fragmentation due to the excess energy. Chemical ionization by $\mathrm{H}_{3} \mathrm{O}^{+}$, which has a relatively moderate proton affinity $(\mathrm{PA}=166.5 \mathrm{kcal} / \mathrm{mol})$ among the Brønsted acid reagent ions, leads to moderate fragmentation patterns. Break-up patterns of molecular ions are highly dependent on functional groups as summarized in Table 1. In addition, for PTR-MS applications, higher ratios of the electric field strength to the number density in the drift tube $(\mathrm{E} / \mathrm{N})$ cause a more pronounced degree of fragmentation (Kim et al., 2009, Tani et al., 2003). Usually, $\mathrm{E} / \mathrm{N}$ is set in the range between 100 and $140 \mathrm{Td}\left(10^{-17} \mathrm{~V} \mathrm{~cm}^{2}\right)$ and the experimental results presented here were collected at $\mathrm{E} / \mathrm{N}$ of $\sim 120 \mathrm{Td}$ (unless otherwise noted). In this section, we will semi-quantitatively discuss fragmentation patterns of the BVOC relevant to this study. More quantitative information can be founded in the studies refereed in the discussion.

Typically, MT (Tani et al., 2003) and SQT (Dhooghe et al., 2008; Kim et al., 2009; Demarcke et al., 2009) decompose by splitting off the same $56 \mathrm{amu}\left(\mathrm{C}_{4} \mathrm{H}_{8}\right)$ neutral fragment. This leaves the fragment ions $m / z 81^{+}$for MT and $m / z 149^{+}$ for SQT as the dominant fragments regardless of the structure of the isomers. Chemical structure, however, can affect the relative abundances of the parent and fragment ions. $p$-Cymene, a monoterpenoid compound with the molecular mass of $134 \mathrm{amu}$ has a neutral $\mathrm{C}_{3} \mathrm{H}_{6}$ fragment that leads to an ion detected at $\mathrm{m} / \mathrm{z} 93^{+}(\sim 50 \%$ abundance at $\sim 120 \mathrm{Td}$; Tani et al., 2003). This implies that $p$-cymene could be a significant interference for toluene measurements in environments with large $p$-cymene concentrations. Therefore, complementary methods such as GC-MS should be employed to estimate toluene emissions from plants with careful assessments of $m / z 93^{+}$signals from $p$-cymene (Heiden et al., 1999; White et al., 2009).

During proton transfer reactions, alcohols tend to split off a $\mathrm{H}_{2} \mathrm{O}$ group as the major neutral fragment. This leads for example to a relatively small parent ion abundance for MBO $(20-30 \%)$ and a negligible parent ion abundance (e.g., less than 5\%) for substituted MT alcohols, such as linalool (Demarcke et al., 2009) or borneol. Substituted MT alcohols are therefore detected at the same masses as MT, $m / z 81^{+}$ and $137^{+}$. Bornyl acetate $(\mathrm{MW}=196)$ is also detected at 
Table 1. A summary of fragmentation patterns of BVOC, relevant to this study. Major product ions (relative abundance $>10 \%$ ) are listed and minor product ions are listed in the brackets at a drift tube energy of $\sim 120 \mathrm{Td}$.

\begin{tabular}{|c|c|c|}
\hline Classes & Species & Fragments \\
\hline Terpenoid & $\begin{array}{l}\text { *Monoterpenes (M. W. 136) } \\
{ }^{+} \text {Sesquiterpenes (M. W. 204) } \\
{ }^{*} \text { p-cymene (M. W. 134) }\end{array}$ & $\begin{array}{l}\mathrm{m} / 281^{+} \text {and } 137^{+}\left(67^{+}, 93^{+} \text {and } 95^{+}\right) \\
m / z 149^{+} \text {and } 205^{+}\left(81^{+}, 95^{+}, 109^{+}, 123^{+}, 135^{+} \text {, and } 137^{+}\right) \\
m / z 93^{+} \text {and } 135^{+}\end{array}$ \\
\hline Alcohol & $\begin{array}{l}\text { MBO (M. W. 86) } \\
\text { Linalool (M. W. 155) } \\
\text { Borneol (M. W. 155) }\end{array}$ & $\begin{array}{l}m / z 69^{+} \text {and } 87^{+}\left(41^{+}\right) \\
m / z 81^{+} \text {and } 137^{+} \\
m / z 81^{+} \text {and } 137^{+}\end{array}$ \\
\hline Ketone & $\begin{array}{l}* * \text { nopinone (M. W. 138) } \\
* \text { camphor (M. W. 152) }\end{array}$ & $\begin{array}{l}m / z 139^{+}\left(121^{+}\right) \\
m / z .153^{+}\end{array}$ \\
\hline Aldehyde & $\begin{array}{l}\text { glycolaldehyde (M. W. 60) } \\
{ }^{* *} \text { pinonaldehyde (M. W. 168) } \\
{ }^{++} \text {Caronaldehyde (M. W. 168) } \\
\text { HMPr (M. W. 88) }\end{array}$ & $\begin{array}{l}m / z 61^{+} \text {and } 43^{+} \\
m / z 151^{+}, 107^{+} \text {, and } 71^{+}\left(43^{+}, 81^{+}, 99^{+}, 109^{+}, 123^{+} \text {, and } 169^{+}\right) \\
m / z 169^{+}, 151^{+} \text {, and } 123^{+}\left(107^{+}, 109^{+}, 125^{+}, 139^{+} \text {, and } 151^{+}\right) \\
m / z 71^{+} \text {and } 89^{+}\end{array}$ \\
\hline Epoxide & $\alpha$-pinene oxide (M. W.152) & $m / z 153^{+}, 135^{+}, 109^{+}\left(43^{+}, 93^{+}\right.$, and $\left.95^{+}\right)$ \\
\hline Ether & methyl chavicol (M. W. 148) & $m / z .149^{+}$ \\
\hline Ester & ${ }^{+++}$Methyl salicylate (M. W. 152) & $\mathrm{m} / \mathrm{z} 153^{+}$ \\
\hline
\end{tabular}

* Tani et al. (2003 and 2004), ** Wisthaler et al. (2001) and Schoon et al. (2004)

+ Kim et al. (2009) and Demarcke et al. (2009), ${ }^{++}$Schoon et al. (2004), ${ }^{++}+$Karl et al. (2008)

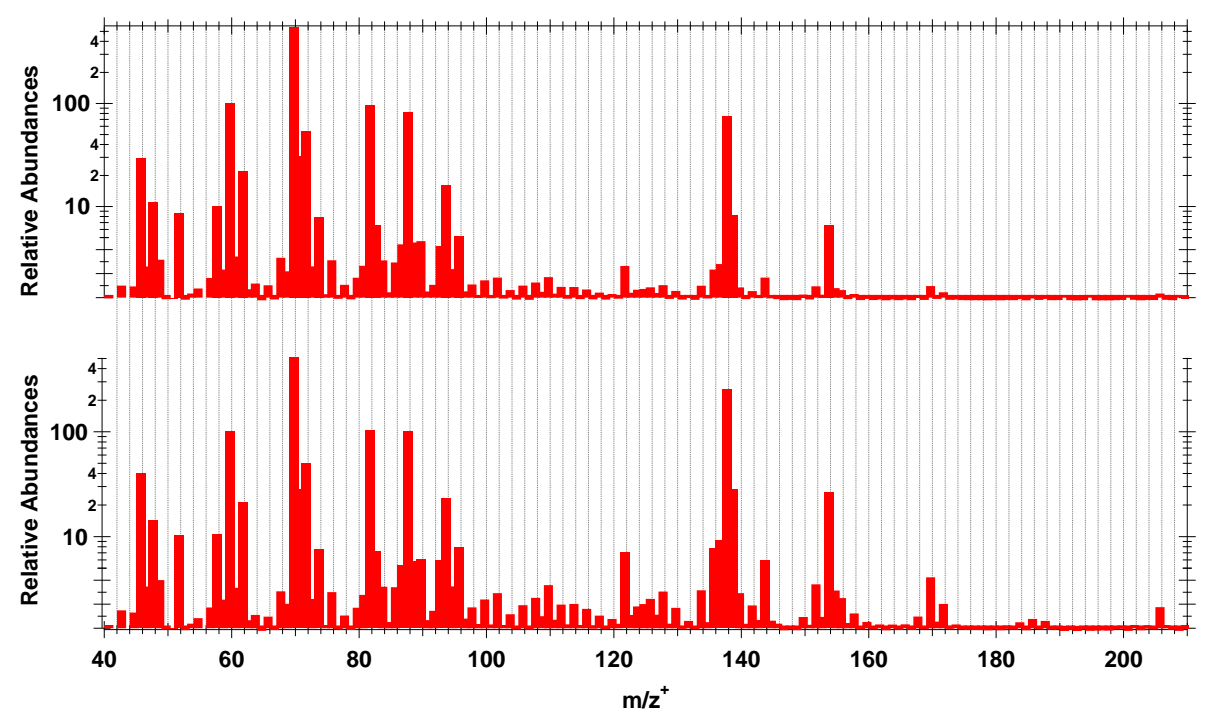

Fig. 1. (a) An averaged mass spectrum and (b) an averaged transmission-corrected mass spectrum from branch enclosure measurements (11 a.m. to 3 p.m. of 12 August to 14 August 2008).

$\mathrm{m} / \mathrm{z} 137^{+}$and $81^{+}$after losing a neutral fragment with the molecular composition of $\mathrm{C}_{2} \mathrm{H}_{4} \mathrm{O}_{2}$. Many studies have reported noticeable emissions of these oxygenated terpenoid compounds (e.g., Ciccioli et al., 1999); thus, care needs to be taken when estimating MT emissions based on PTR-MS alone. The protonated ions of most aldehyde and epoxide species tend to lose $\mathrm{H}_{2} \mathrm{O}$ in the drift tube as summarized in Table 1. Two ketoaldehyde species, pinonaldehyde and caronaldehyde, are first generation oxidation products of $\alpha$ pinene and 3-carene, respectively. The fragmentation pattern 
Table 2. Observed compounds/compound classes, product ions and abundances (\%) in the transmission-corrected mass spectrum (3rd column). The proton transfer reaction rate corrected abundances (PTR Corr. Abd., \%) along with proton transfer rate constants (PTR constants in $10^{-9} \mathrm{~cm}^{3} \mathrm{~s}^{-1}$ ) are also summarized in 6 th and 5th column.

\begin{tabular}{|c|c|c|c|c|c|}
\hline Species & $\begin{array}{l}\text { Product Ions } \\
(\mathrm{m} / \mathrm{z})\end{array}$ & Abundances & Detected Species & PTR Constants & PTR Corr. Abd. \\
\hline MBO & $69^{+}$and $87^{+}$ & 50.74 & & 2.6 & 50.15 \\
\hline MT & $81^{+}$and $137^{+}$ & 29.97 & $\begin{array}{l}\beta \text {-pinene }(25.1 \%), 3 \text {-carene }(17.1 \%) \text {, } \\
\text { limonene }(15 \%), \text { myrcene }(17.3 \%) \text { and } \\
\text { ten other species }\end{array}$ & 2.3 & 33.48 \\
\hline MT in other masses & $93^{+}, 133^{+}$, and $135^{+}$ & 2.81 & $\begin{array}{l}p \text {-cymene, } o \text {-cymene, } \\
\text { and menthatriene }\end{array}$ & 2.4 & 3.05 \\
\hline oxygenated-MT & $153^{+}$and $151^{+}$ & 2.49 & $\begin{array}{l}\text { verbenone, car-3-en-2-one, } \\
\text { and carvone }\left(\mathrm{m} / \mathrm{z} 151^{+}\right) \text {, } \\
\text { and mostly camphor }\left(\mathrm{m} / \mathrm{z} 153^{+}\right)\end{array}$ & 4.4 & 1.45 \\
\hline$m / z 169+$ & $169^{+}$ & 0.36 & & & \\
\hline SQT & $205^{+}$ & 0.15 & mostly isolongifolene & 3.0 & 0.13 \\
\hline Acetaldehyde & $45^{+}$ & 3.36 & & 3.4 & 2.57 \\
\hline Acetone & $59^{+}$ & 8.35 & & 3.0 & 7.15 \\
\hline Acetic Acid & $61^{+}$ & 1.79 & & 2.3 & 2.02 \\
\hline
\end{tabular}

of pinonaldehyde has been reported twice using two different ion reaction chamber configurations-a drift tube (PTR-MS; Wisthaler et al., 2001) and a flow tube (SIFT-MS; Schoon et al., 2004). Results from the two studies are qualitatively similar in that the dehydrated fragment ion $\left(\mathrm{m} / \mathrm{z}, 151^{+}\right)$is the dominant product; other observed fragment ions exhibit the same masses but are more abundant in PTR-MS mass spectra due to extra kinetic energy in the drift tube reactor of PTR-MS. The fragment ion distribution of caronaldehyde observed by the SIFT-MS technique is slightly different from that of pinonaldehyde observed by SIFT-MS. Along with the dehydrated ion $\left(\mathrm{m} / z 151^{+}\right)$, a significant fraction of the parent ion $\left(\mathrm{m} / \mathrm{z} 169^{+}\right)$and another major fragment $\left(\mathrm{m} / \mathrm{z} 123^{+}\right)$ were observed, both with abundances comparable to that of $m / z 151^{+}$. These differences could originate from structural differences of the two compounds (e.g., the ring systems). The results suggest that fragmentation patterns of other first generation oxidation products of MTs (e.g. limonenaldehyde) need to be examined for the accurate assessment of product ion yields in photochemical kinetic studies (e.g., $\mathrm{Ng}$ et al., 2006). Finally, ketones and ethers listed in the table are detected mostly (>90\%) at the parent ion masses.

\subsection{BVOC Emissions from ponderosa pine}

For the first week of the field campaign, a PTR-MS system was set up to measure mass spectra from a branch enclosure. A three-day averaged mass spectrum (12 August to 14 August 2008) of the branch enclosure sample is presented in Fig. 1a for daytime (11 a.m. to 3 p.m.) condi- tions. Fig. $1 \mathrm{~b}$ presents the transmission-corrected spectrum. The scale on the $y$-axis represents the relative abundance of the mass spectra normalized to the acetone peak $\left(\mathrm{m} / z 59^{+}\right)$. Based on the fragmentation patterns, summarized in Table 1, the identified BVOC species and their relative abundances in the transmission-corrected spectrum are summarized in Table 2. The table also summarizes the speciation of MT, oxygenated-MT, and SQT, identified by GC-MS and available proton transfer reaction rates of each species. Emission strengths measured by PTR-MS are proportional to the relative abundances normalized by proton transfer reaction constants as summarized in the last column of Table 2. MBO and MT are the dominant BVOCs emitted from ponderosa pine as observed in earlier studies (Baker et al., 2001). The emission strength of MT that was measured by GC-MS is $\sim 72 \%$ of that measured by PTR-MS, a result consistent with the findings of Lee et al. (2005), who suggested the existence of reactive MT that can only be measured by PTR-MS. Less than $5 \%$ of the discrepancy can be explained by the contributions of oxygenated MT, such as linalool and bornyl acetate, which were detected on $m / z 81^{+}$and $137^{+}$. In addition, the GC-MS detected elevated levels of toluene from the branch enclosure ( $\sim 4$ times higher than ambient concentration). With subtraction of the $p$-cymene background based on the results of Tani et al. (2004), we can estimate that toluene emissions were less than $1 \%$ of MT emissions. This is much lower than the reported value for stressed pine needles but similar to that observed for unstressed needles by Heiden et al. (1999). Although pronounced acetone, acetaldehyde and acetic acid 
Table 3. Daily variations of emission rates of four BVOC observed from branch enclosures, measured by PTR-MS. Leaf cuvette measurement results are also summarized for measurements made at the same ecosystem with different ponderosa pine trees. Emission capacity $\left(\mathrm{E}_{30}\right)$ and $\beta$ (Guenther et al., 1993) derived from this study and previous studies of ponderosa pine in different ecosystems are also presented.

\begin{tabular}{|c|c|c|c|c|c|}
\hline Date & $\operatorname{MBO}\left(\mu \mathrm{gg}^{-1} \mathrm{hr}^{-1}\right)$ & MT $\left(\mu \mathrm{gg}^{-1} \mathrm{hr}^{-1}\right)$ & oxygenated-MT $\left(\mu \mathrm{g} \mathrm{g}^{-1} \mathrm{hr}^{-1}\right)$ & SQT $\left(\mu \mathrm{gg}^{-1} \mathrm{hr}^{-1}\right)$ & Temp $\left({ }^{\circ} \mathrm{C}\right)$ \\
\hline 21 August 2008 & 4.85 & 3.6 & 0.400 & 0.0343 & 30.9 \\
\hline 25 August 2008 & 4.67 & 4.66 & 0.438 & 0.0825 & 30.5 \\
\hline 26 August 2008 & 5.07 & 4.52 & 0.460 & 0.0453 & 30.3 \\
\hline 27 August 2008 & 4.56 & 3.67 & 0.427 & 0.0425 & 30.7 \\
\hline 28 August 2008 & 3.57 & 2.44 & 0.197 & 0.0243 & 27.0 \\
\hline 2 September 2008 & 2.43 & 1.81 & 0.156 & 0.0179 & 24.3 \\
\hline 3 September 2008 & 3.08 & 1.51 & 0.130 & 0.00641 & 28.9 \\
\hline 4 September 2008 & 2.47 & 1.02 & 0.109 & 0.00623 & 26.4 \\
\hline $\begin{array}{c}* * 30 \text { July to } \\
25 \text { September } 2008\end{array}$ & $4.70(2.43)$ & $1.97(0.73)$ & & $* * * \mathrm{NA}$ & \\
\hline Basal Emission & $\mathrm{E}_{30}=3.92$ & $\begin{array}{c}\mathrm{E}_{30}=2.4, \\
\beta=0.15\end{array}$ & & $\begin{aligned} \mathrm{E}_{30} & =0.0218, \\
\beta & =0.16\end{aligned}$ & \\
\hline \multirow[t]{2}{*}{ Previous Studies } & ${ }^{++} E_{30}>7$ & $\begin{array}{c}{ }^{*} \mathrm{E}_{30}=0.163-1.455, \\
{ }^{*} \beta=0.159-0.781\end{array}$ & & $\begin{array}{c}{ }^{*} \mathrm{E}_{30}=0.080-0.100, \\
{ }^{*} \beta=0.209-1.763\end{array}$ & \\
\hline & & $\begin{array}{c}{ }^{+} E_{30}=0.5, \\
\beta=0.11\end{array}$ & & $\begin{array}{c}{ }^{+} \mathrm{E}_{30}=0.070, \\
\beta=0.15\end{array}$ & \\
\hline
\end{tabular}

${ }^{*}$ Bouvier-Brown et al. (2009); ${ }^{* *}$ Leaf cuvette-GC FID measured averages (for a total of 12 days in the periods)

${ }^{* * *}$ Mostly under the detection limit; ${ }^{+}$Helmig et al. $(2007) ;{ }^{+}$Harley et al. (1998)

(the GC-MS results confirmed acetic acid rather than glycolaldehyde, also detected at the same $\mathrm{m} / z$ of $61^{+}$) peaks were observed in the spectrum, the flux of these compounds is strongly dependent on their compensation point and on the concentrations in the surrounding air. Since their concentration in the branch enclosure differs from that of ambient air, ecosystem-scale flux measurements would be preferable to estimate their fluxes (Kesselmeier et al., 1997; Schade and Goldstein, 2001; Karl et al., 2005; Jardine et al, 2008). The total counts listed in Table 2 represent $93 \%$ of the total counts in the spectrum of Fig. 1b. This suggests that we have a reasonably good understanding of the composition of BVOC emissions from these ponderosa pine in the mass spectral range investigated here for compounds that can be detected by PTR-MS. However, the lower sensitivities of PTR-MS techniques for high mass compounds of PTR-MS techniques (M.W.> 150) could mean that we are missing some heavier compounds.

After a week of conducting mass scan measurements, we changed the PTR-MS measurement mode to multiple ion detection, which enables shorter averaging times due to a better signal to noise ratio. These measurements were conducted for three weeks, focusing on emission rates of MBO, MT, SQT, and oxygenated-MT $\left(m / z=153^{+}\right)$. Mean measured daytime emission rates (11 a.m. to 3 p.m.) along with daily temperature variations are summarized in Table 3. The average emission ratios for MT/MBO and SQT/MT were 0.72 $( \pm 0.16)$ and $0.01( \pm 0.004)$, respectively. During the same campaign we conducted ecosystem-scale gradient measurements using a second PTR-MS instrument. From these we calculated an ecosystem-scale flux ratio of $0.50 \pm 0.15$ and $0.04 \pm 0.01$ for MT/MBO and SQT/MT respectively. The results can be interpreted in the context of chemical reactivity inside of the forest canopy. More comprehensive approaches including investigations of photochemical processes inside of the forest canopy and measurements on a large number of branches to characterize branch-to-branch variability are planned for future studies at the MFO site and will address these differences more quantitatively. Emission rates of oxygenated-MT listed in Table 3 are calculated based on the signals on $\mathrm{m} / \mathrm{z} 153^{+}$, the sensitivity measured for MT and the proton transfer reaction rate of camphor $\left(4.4 \times 10^{-9} \mathrm{~cm}^{3} \mathrm{~s}^{-1}\right.$; Tani et al., 2003). The estimated emission rates are significantly lower than those of MT but much higher than SQT emission rates, though daily emission rate variations of SQT indicate a wide range (e.g., one order of magnitude). Such large emission variations have been reported previously on longer timescales (Arey et al., 1995; Ciccioli et al., 1999; Vuorinen et al., 2005; Ruuskanen et al., 2007, BouvierBrown et al., 2009) but the underlying endogenous (e.g., developmental stage of branch) and exogenous (e.g., temperature and light) controlling factors remain uncertain. Table 3 also contains the results from an exponential fitting function between temperature and emission rates used to parameterize emissions. 
The exponential fitting scheme is analogous to the algorithm of Guenther et al. (1993), $\mathrm{E}($ temp $)=\mathrm{E}_{30} \exp (\beta$ temp30 ), where $\mathrm{E}_{30}$ indicates the emission capacity at $30^{\circ} \mathrm{C}$ for a given dry needle mass and $\beta$ indicates the temperature response factor. Analogous measurements of $\mathrm{E}_{30}$ and $\beta$ from recent ponderosa pine studies are also shown in Table 3 . The $\beta$-values determined in the different studies show reasonable agreement, although the small differences (e.g. $\sim 0.05$ ) in $\beta$ could still lead to significant differences in BVOC emission estimation. Emission capacity varies significantly between different studies. Leaf cuvette measurements of various ponderosa pine trees at the Manitou forest site (Table 3) indicated reasonable agreement with the branch emission measurement results for MBO and MT. In addition, the low emissions of SQT in the branch enclosure measurement were consistent with the results of leaf cuvette measurements for various ponderosa pine individuals. Bouvier-Brown et al. (2009) observed large variations of emission capacity (factor of 8) for different ponderosa pine individuals at a different ecosystem (the Blodgett Forest research station) suggesting that plantto-plant variations among the same species in an ecosystem can be significant although some of the variability is likely caused by artifacts associated with enclosure measurement techniques. These relatively large emission variations, again, have been reported from experiments for many plant species and ecosystems and could be caused by biotic or abiotic stresses (e.g. herbivory and violent weather events; Duhl et al., 2008).

\subsection{BVOC and their oxidation product distributions in the forest canopy}

Figure 2 presents the diurnal variations of ambient concentrations of MBO, MT, acetone $\left(\mathrm{m} / z 59^{+}\right)$and glycolaldehyde+acetic acid $\left(\mathrm{m} / z 61^{+}\right)$, averaged over a three-week period (18 August to 6 September 2008). The diurnal variations of MBO and MT, two major BVOC emitted by the ecosystem, show a clear opposite pattern. Emissions of MBO are strongly light dependent (Harley et al., 1998) leading to maximum mixing ratios during the day despite a shorter chemical lifetime and dilution into a deeper boundary layer. A similar diurnal trend was also observed at a ponderosa pine ecosystem in California (Schade and Goldstein, 2001). On the other hand, the lower boundary layer depth during the night along with higher oxidant mixing-ratios (e.g. $\mathrm{OH}$ and ozone) during the day seems to be the main controlling factor of the diurnal variation of MT concentrations, with maximal mixing ratios occurring at early morning despite lower emissions resulting from cooler temperatures (Hewitt et al., 1995). The dominant MT species observed during the field campaign period was $\beta$-pinene (26\%), followed closely by $\alpha$-pinene (22\%) and 3-carene (21\%). The results correspond with emission measurements from the branch enclosure system. The diurnal variation of compounds with sources that include both direct emissions and BVOC oxidation such as acetone, possibly contributed by direct emissions, and acetic acid is more complex. The main reason is the interplay between photochemical production during daytime and variations in boundary layer height throughout the day.

In order to compare differences in diurnal oxidation product distributions between the day when MBO was the dominant BVOC emission and the night when MT was the dominant BVOC emission, Fig. 3 shows an MBO-dominated daytime spectrum (2 to 3 p.m. on 14 August; Fig. 3a) as well as a MT-dominated nighttime spectrum (1 to 2 a.m. on 18 August; Fig. 3b). Figure $3 c$ and $d$ present transmission-corrected mass spectra for day and night, respectively. Transmissioncorrected spectra were calculated based on acetone $\left(\mathrm{m} / z 59^{+}\right)$ as a reference mass. Major peaks and their transmissioncorrected counts from the spectra are summarized in $\mathrm{Ta}$ ble 4. The table also shows mixing ratios of $\mathrm{NO}_{y}$ and $\mathrm{SO}_{2}$ during the time period, which indicate that the air masses were not significantly influenced by pollution, a conclusion supported by the relatively weak peak strengths of benzene $\left(79^{+}\right)$and toluene $\left(93^{+}\right)$, even though ambient toluene concentrations from PTR-MS measurements might reflect an upper limit. Formic acid exhibits the highest contribution during both day and night. Other oxidation products (acetaldehyde, acetone, acetic acid+glycolaldehyde, 2-hydroxy-2methylpropanal (HMPr), methyl ethyl ketone (MEK)) were also detected in significant amounts. $m / z 153^{+}$, most likely an oxygenated-MT (e.g., camphor), was also detected in significant amounts during both day and night. A number of studies using GC techniques have reported emissions of oxygenated-MT that could be detected on $m / 2153^{+}$by PTRMS. Noticeable emissions of camphor and other oxygenatedMT have been reported especially from conifers (Ortega et al., 2008). In this ecosystem, we confirmed the emission of oxygenated-MT based on both GC-MS and PTR-MS measurements. At the same time, we also observed the compound class with significant concentrations in ambient air. In addition, some unidentified masses in the spectra are summarized in Table $4, \mathrm{~m} / 275^{+}, 57^{+}$, and $101^{+}$(hydroxyacetone, a fragment of hydroxyacetone, and C5 hydroxycarbonyl, respectively) in the table could be attributable to oxidation products of isoprene (Paulot et al., 2009), which is a minor BVOC emission from this ecosystem but is emitted in greater amounts from some upwind ecosystems. Indeed, only small amounts of isoprene $(\sim 0.1-0.3 \mathrm{ppbv})$ were found in canister samples, collected on site and analyzed via GCMS. The concentrations did not show any strong diurnal variation, suggesting that isoprene at this site is transported from other ecosystems (e.g., aspen groves, oak shrublands, spruce forests, riparian willow zone) with isoprene oxidation products produced during transport. The significance of transported isoprene oxidation products in a ponderosa pine dominated ecosystem was also reported by Dreyfus et al. (2002) at the Blodgett Forest research station in California. The compounds/compound classes listed in Table 4 (including $m / z 75^{+}, 57^{+}$and $101^{+}$) account for $76 \%$ and $75 \%$ of the 


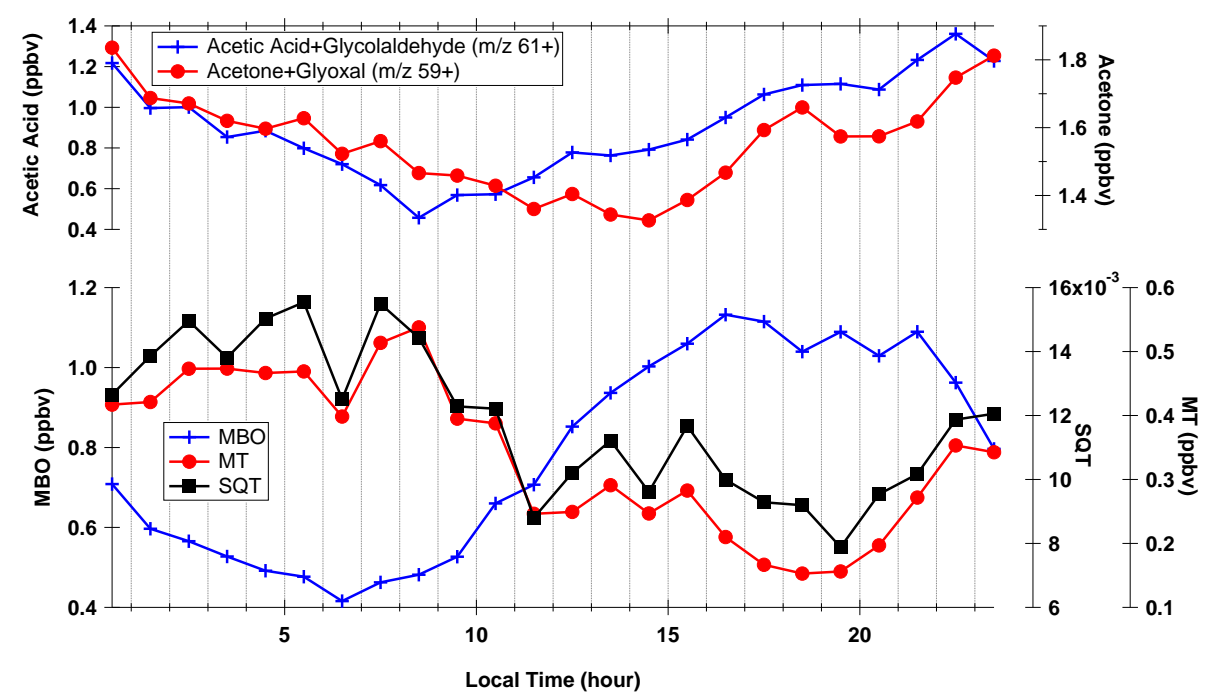

Fig. 2. Averaged diurnal variations of BVOC and their oxidation products for three weeks in the summer of 2008 (18 August to 6 September)
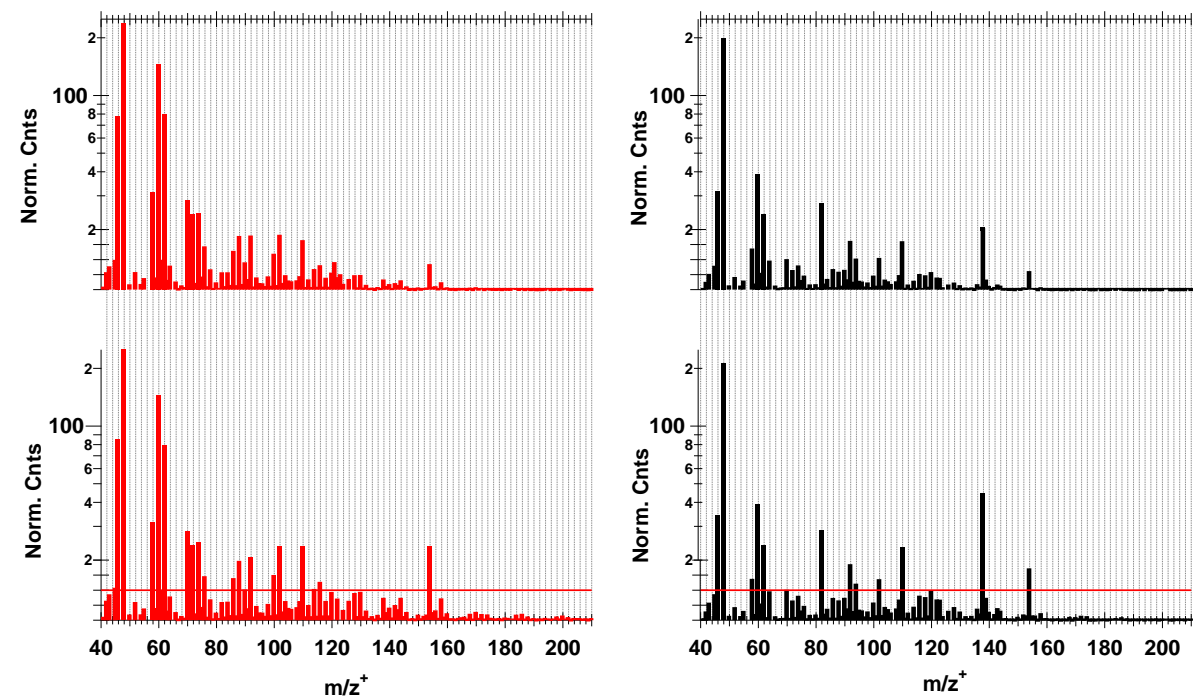

Fig. 3. Representative ambient mass spectra of (a) the daytime ( 2 to 3 p.m. on 14 August 2008) and (b) the nighttime (1 to 2 a.m. on 18 August 2008) periods. Their transmission corrected mass spectra are presented in (c) and (d), respectively.

observed ambient mass spectra (without the inclusion of even masses to focus on hydrocarbon $\left(\mathrm{C}_{x} \mathrm{H}_{y}\right)$ and oxygenatedhydrocarbon $\left(\mathrm{C}_{x} \mathrm{H}_{y} \mathrm{O}_{z}\right)$ compounds) during day and night respectively. The larger fraction of unidentified counts in ambient mass spectra $(\sim 24 \%)$, compared to those observed from branch enclosure measurements $(\sim 7 \%)$, suggests the influence of photochemical VOC production observed in this clean environment. The discussion, again, is limited due to the low sensitivity of PTR-MS for higher mass compounds. Recent technical breakthroughs such as a time-of-flight detector or ion trap mass spectrometers are expected to expand our understanding of the chemistry of semi-volatile organic compounds (Mielke et al., 2008; Jordan et al., 2009).

\subsection{Laboratory kinetics experiments}

To quantitatively assess contributions of oxidation products of BVOC in this eco-system, we conducted laboratory oxidation experiments for two major BVOC emissions, MBO and $\beta$-pinene in dry conditions. $\mathrm{OH}-$ and ozone-initiated oxidation products and their yields from $\beta$-pinene have been previously quantified with PTR-MS by Wisthaler et al. (2001) and Lee et al. (2006), respectively but the products of $\mathrm{OH}$ or ozone initiated oxidation of MBO have not been reported with PTR-MS. For each oxidation experiment, the PTR-MS was operated in a mass-scanning mode $\left(\mathrm{m} / 240^{+}\right.$ to $210^{+}$). The mass range is much wider than those from 


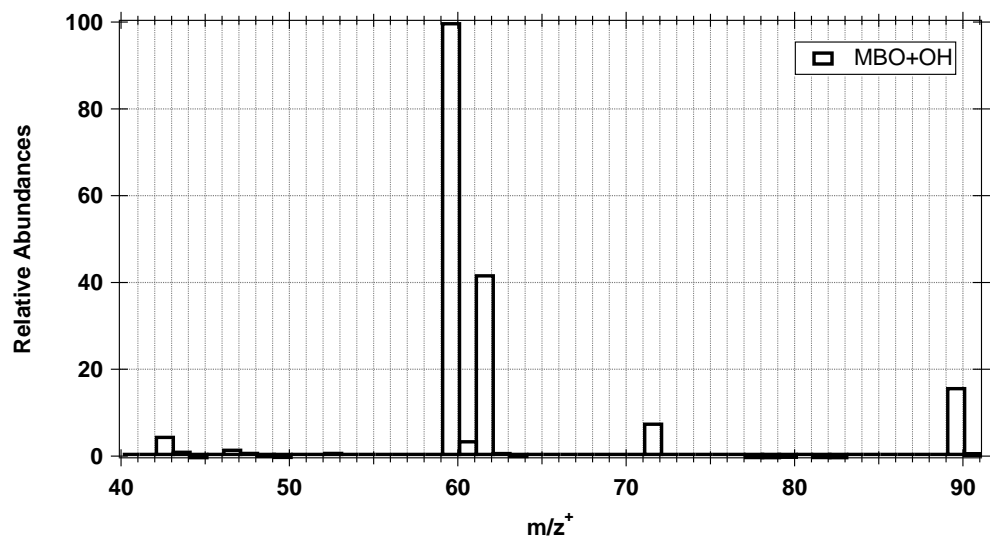

Fig. 4. The transmission-corrected PTR-MS spectrum of the $\mathrm{OH}$ initiated MBO oxidation experiment.

Table 4. Major peaks in the ambient transmission corrected spectra and their normalized counts (Fig. 3).

\begin{tabular}{llcc}
\hline Species & $m / z^{+}$ & \multicolumn{2}{c}{ Transmission Corrected Counts } \\
Day & Night \\
\hline Acetaldehyde & 45 & 84.73 & 34.28 \\
Formic Acid & 47 & 251.75 & 211.63 \\
Acetone & 59 & 145.06 & 39.02 \\
Acetic Acid & 61 & 79.19 & 24.01 \\
MBO & 69 and 87 & 48.07 & 16.71 \\
HMPR & 71 and 89 & 34.20 & 13.99 \\
Methyl Ethyl Ketone & 73 & 24.64 & 8.11 \\
MT & 81 and 137 & 13.52 & 73.59 \\
Oxygenated-MT & 153 & 23.66 & 17.27 \\
*MS75 & 75 & 14.64 & 4.76 \\
**MS57 & 57 & 31.46 & 13.76 \\
+MS101 & 101 & 23.59 & 13.65 \\
MS109 $_{\text {NO }}$ & 109 & 23.70 & 23.19 \\
$\mathrm{SO}_{2}$ & & $5.2 \mathrm{ppbv}$ & $2.7 \mathrm{ppbv}$ \\
& & $0.36 \mathrm{ppbv}$ & $0.06 \mathrm{ppbv}$ \\
\hline
\end{tabular}

*Possibly hydroxy acetone

** Possibly butene or fragment of hydroxy acetone

+ Possibly C5 hydroxycarbonyl

Table 5. Relative abundances of the $\mathrm{OH}$ initiated oxidation products of MBO. The estimated fractional molar product yields are presented in the brackets. The glycolaldehyde abundance and yield are calculated with considerations of the fragmented portion $(\sim 50 \%$, see the text for details)

\begin{tabular}{lcc}
\hline Products & PTR-MS & $*$ FT-IR \\
\hline Formaldehyde & NA & $0.29-0.35$ \\
Acetone & $100(0.51)$ & $0.52-0.67$ \\
HMPr & $23.7(0.14)$ & $0.19-0.31$ \\
glycolaldehyde & $83.8(0.43)$ & $0.50-0.78$ \\
\hline
\end{tabular}

${ }^{*}$ Carrasco et al. (2007) and Atkinson and Arey (2003) the previous studies of $\beta$-pinene oxidation experiments especially towards the higher mass end. A background mass spectrum for $\mathrm{OH}$ oxidation experiments was taken for all chemicals (e.g. MBO, NO, organic nitrite, and air matrix $\sim 800$ torr) introduced into the environmental chamber. For ozone experiments, we also obtained background spectra before ozone was injected into the environmental chamber. The background mass spectrum was observed before each batch of experiments. As oxidation reactions progressed, spectra were taken and the blank spectrum subtracted to get the net product distribution spectra due to photo-oxidation.

An example of a net spectrum is presented in Fig. 4. The mass discrimination-corrected spectrum in the figure shows the product distributions from the oxidation of MBO by $\mathrm{OH}$. Peaks of the spectrum are normalized by ace-

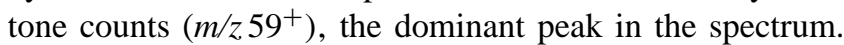
Other pronounced peaks can be matched with known product molecular ions such as 2-hydroxy-2-methylpropanal (HMPr, $\left.\mathrm{m} / z 89^{+}\right)$and its dehydrated ion $\left(\mathrm{m} / z 71^{+}\right)$, and glycolaldehyde $\left(\mathrm{m} / z 61^{+}\right)$. Although acetic acid could be detected on the same mass, the possibility was excluded from the FT-IR data. The protonated glycolaldehyde ion was shown to have a dehydrated fragment of $m / z 43^{+}$with intensity equal to the parent ion abundance in the $\mathrm{E} / \mathrm{N}$ configuration of laboratory experiments $(\sim 130 \mathrm{Td})$. However, due to interferences from $\mathrm{OH}$ precursors on $\mathrm{m} / \mathrm{z}^{4} 3^{+}$, the pronounced peak at this mass could not be quantified in the product distribution spectrum. The relative abundances of products and their product yields (brackets) calculated from spectra are summarized in Table 5. The table also shows product yields calculated from previous FT-IR experiments (Carrasco et al., 2007 and Atkinson and Arey, 2003 and references therein). Overall, the FT-IR observed product yields of this study show reasonable agreement with previous studies. The estimated yield of acetone from the PTR-MS experiments in Table 5 shows reasonable agreement with previous FT-IR experiment results. The glycolaldehyde yield is estimated from the calculated proton transfer reaction constant $\left(\mathrm{k}_{\mathrm{AOD}}=2.97 \times 10^{-9} \mathrm{~cm}^{3} \mathrm{~s}^{-1}\right.$ 
from the average-dipole-orientation theory) and the estimated product ion counts, twice that of the parent ion $\left(\mathrm{m} / \mathrm{z}_{61} \mathrm{1}^{+}\right)$counts in the spectrum, to account for fragmentation. The HMPR yield in the table was also calculated based on the calculated proton transfer reaction constant $\left(\mathrm{k}_{\mathrm{AOD}}=2.80 \times 10^{-9} \mathrm{~cm}^{3} \mathrm{~s}^{-1}\right.$ from the average-dipoleorientation theory). PTR-MS detected acetone, HMPr and formic acid and FT-IR detected formaldehyde, acetone, and formic acid as major ozone-initiated oxidation products of MBO in dry conditions. Carrasco et al. (2007) reported the same results in dry conditions. However, the same study also found that only HMPr and formaldehyde are detected as oxidation products in humid condition (R.H.> 20\%).

Product distributions of $\beta$-pinene oxidation with $\mathrm{OH}$ and ozone indicate reasonable agreement with previously reported results (Wisthaler et al., 2001; Lee et al., 2006; Atkinson and Arey, 2003 and references there in). Both PTR-MS and FT-IR measured nopinone as a major oxidation product. FT-IR detected formaldehyde and acetone and PTR-MS detected acetone, formic acid, hydroxy nopinone (only by ozone oxidation), and 3-oxonopinone as oxidation products. PTR-MS detected relatively small amounts of $m / z 169^{+}$in the product spectrum by ozone-initiated oxidation. The peak is possibly from dehydrated fragments of protonated pinic acid $\left(\mathrm{m} / \mathrm{z} 187^{+}\right)$. The product mass spectrum of $\mathrm{OH}$ oxidation experiments indicates pronounced $m / z 101^{+}$(with a relative abundance of 25.7) similar to what we observed in the ambient spectra at the Manitou forest site. However, the fact that the nopinone signal $\left(\mathrm{m} / z 139^{+}\right)$is relatively weak in the ambient spectrum prevents us from speculating that the significant $m / 2101^{+}$signal in the ambient spectrum is from a $\beta$-pinene oxidation product. The oxidation products abundances described above explain $75.9 \%$ of total counts in the $\mathrm{OH}$ oxidation spectrum and $75.4 \%$ of total counts from the ozone oxidation spectrum. For comparison, about $95 \%$ of the total counts from MBO oxidation experiments could be attributed to the known compounds.

To compare the product distributions of the oxidation experiments with the daytime ambient spectrum in the forest canopy, we conducted a simple time-dependent calculation to get ratios of (glycolaldehyde)/(MBO) and (nopinone) $/(\beta$ pinene). The calculations were constrained by the measured daily variations of MT, MBO (Fig. 2) and ozone. Daily variations of $\mathrm{OH}$ concentrations were set to follow daily variations of $\mathrm{J}_{\mathrm{NO}_{2}}$, calculated by the TUV (Total Ultraviolet and Visible http://cprm.acd.ucar.edu/Models/TUV/) model with a maximum value of $2.5 \times 10^{6}$ molecules $\mathrm{cm}^{-3}(\mathrm{OH})$. The absolute $\mathrm{OH}$ concentrations are not important for our purpose because we calculate the ratios of the oxidation products and the precursors rather than absolute concentrations of products. The yields of glycolaldehyde and nopinone from MBO and $\beta$-pinene oxidation, respectively, were assigned the values found in this study. The $\mathrm{OH}$ loss rates of glycolaldehyde $\left(k_{\text {glycolaldehyde }-\mathrm{OH}}=1.1 \times 10^{-11}\right.$ at $\left.298 \mathrm{~K}\right)$ and nopinone $\left(k_{\text {nopinone- } \mathrm{OH}}=1.7 \times 10^{-11}\right.$ at $\left.298 \mathrm{~K}\right)$ were taken from Bacher et al. (2001) and Calogirou et al. (1999), respectively. The daily variations of glycolaldehyde and nopinone in the model become consistent in 48 hours of model time. From the stabilized diurnal variations, the average ratios of (glycolaldehyde)/(MBO) $(=1.62)$ and (nopinone)/( $\beta$-pinene) $(=0.824)$ between 2 p.m. to 3 p.m., corresponding to the time period of the average daytime ambient mass spectrum as shown in Fig. 3c. Based on these ratios, a composite spectrum was calculated from four mass spectra obtained in the laboratory oxidation experiments. The oxidation product distribution mass spectra were scaled based on ambient oxidant concentrations of $\mathrm{OH}$ (assumed to be $2.5 \times 10^{6}$ molecules $\mathrm{cm}^{-3}$ ) and ozone (45 ppbv from ambient measurements) and the amount of MBO and $\beta$-pinene in the ambient spectrum of Fig. 3c. The calculated composite spectrum along with the ambient spectrum is presented in Fig. 5 .

The composite spectrum is dominated by the known oxidation products of MBO and $\beta$-pinene such as acetone, glycolaldehyde, HMPr, and nopinone. Those compounds comprised more than half of the total counts in the ambient spectrum as described in the above section. However, a significant fraction of peaks in the ambient spectrum are not present in the composite spectrum. The additional peaks may come from oxidation products of other MT species such as $\alpha$-pinene and 3-carene, which represented $22 \%$ and $20 \%$ of the ambient MT concentrations. However, the relatively weak signal on $m / z 151^{+}$, a major fragment for both pinonaldehyde (an $\alpha$-pinene oxidation product) and caronaldehyde (a 3-carene oxidation product) suggests that photo-oxidation products of these two MTs can only account for a small fraction of unidentified peaks. Therefore, further investigations such as possible oxidation product contributions from oxygenated-MT $\left(\mathrm{m} / z 153^{+}\right)$are necessary. As ambient mass spectra indicated influences of transported oxygenated products of VOC not emitted in the ecosystem (e.g. isoprene), a significant portion of unidentified peaks in the spectra may be attributable to this process. In addition, the possibility of significant emissions of semi-volatile organic compounds, detected by PTR-MS with low sensitivity (i.e. with amu $>150$ ), leads us to speculate that their oxygenated products could contribute to the unidentified peaks, although many studies have demonstrated that a significant portion of oxidation products of SVOC is partitioned into the aerosol phase due to their low vapor pressure (Kroll and Seinfeld, 2008).

\section{Conclusions}

We examined emissions and photochemical processes within a ponderosa pine ecosystem with comprehensive PTR-MS and GC-MS measurements. Most of the peaks in the mass spectra of the branch enclosure emission system could be assigned to known BVOC, which were identified by GC-MS. The identified species comprise most of the signals $(\sim 93 \%)$ in the transmission corrected mass spectrum, observed by 


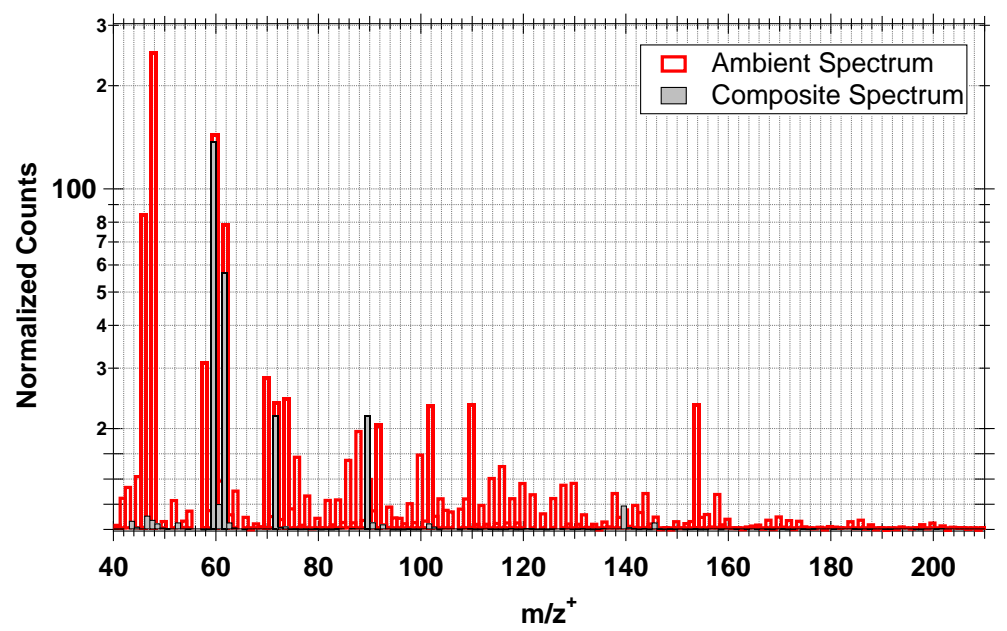

Fig. 5. The transmission corrected daytime ambient mass spectrum (red from Fig. 3c) and the steady-state product distribution spectrum (black) of $\mathrm{MBO}$ and $\beta$-pinene. Detailed procedures for calculating the product distribution spectrum are described in the text.

PTR-MS. Both PTR-MS and GC-MS observed MBO and MT as the major emissions. Emission measurements from a leaf cuvette system with GC-FID analysis showed relatively consistent emission rates of MBO and total MT from different ponderosa pine trees in the ecosystem. Significantly lower amounts of SQT emissions were quantified by PTRMS and GC-MS than emission rates previously reported for ponderosa pines. As the importance of SQT has been highlighted for their significant SOA (secondary organic aerosol) formation potential (Sakulyanontvittaya et al., 2008), comprehensive research on the biotic and abiotic factors controlling SQT emission is necessary. Oxygenated-MT such as camphor were also quantified by both PTR-MS and GCMS. The estimated emission rates were in the range of 0.1 to $0.4 \mu \mathrm{g} \mathrm{g}^{-1} \mathrm{hr}^{-1}$, lower than MT emission rates but significantly higher than SQT emission rates.

The observed ambient temporal variation patterns of $\mathrm{MBO}$ and MT, the major BVOC emitted from the ecosystem, and their major oxidation products, acetone and glycolaldehyde+acetic acid $\left(\mathrm{m} / \mathrm{z} 61^{+}\right)$were controlled by diurnal emission, chemistry, and boundary layer characteristics, and were similar to observations reported previously. In the transmission corrected ambient mass spectrum obtained during daytime, $\sim 76 \%$ of the total signal could be explained by known compounds. To explore sources of unidentified peaks, $\mathrm{OH}-$ and ozone-initiated oxidation spectra of the primary emission species at the site ( $\mathrm{MBO}$ and $\beta$-pinene) were generated using a laboratory chamber facility. In general, the oxidation product distributions in the PTR-MS spectra corresponded with those found in previous studies. Using four different laboratory-derived product distribution spectra (from oxidation of both $\mathrm{MBO}$ and $\beta$-pinene with $\mathrm{OH}$ and ozone), we calculated the oxidation product distribution spectrum of the ecosystem. This spectrum could not explain most of the unidentified peaks. The potential sources for these uniden- tified species include 1) BVOC oxidation products transported from ecosystems upwind, and 2) oxidation products of unidentified BVOC emitted from the ecosystem that are not detected due to analytical limitations of PTR-MS and GC techniques (e.g. semi-volatile organic compounds). Recent technical breakthroughs such as the time-of-flight mass spectrometry technique are expected to address these issues.

Acknowledgements. The National Center for Atmospheric Research is operated by the University Corporation for Atmospheric Research under sponsorship from the National Science Foundation. Any opinions, findings and conclusions or recommendations expressed in this publication are those of the authors and do not necessarily reflect the views of the National Science Foundation.

Edited by: A. Hofzumahaus

\section{References}

Andreae, M. O. and Crutzen, P. J.: Atmospheric aerosols: Biogeochemical sources and role in atmospheric chemistry, Science, 276, 1052-1058, 1997.

Arey, J., Crowley, D. E., Crowley, M., Resketo, M., and Lester, J.: Hydrocarbon emissions from natural vegetation in California south-coast-air-basin, Atmos. Environ., 29, 2977-2988, 1995.

Atkinson, R. and Arey, J.: Gas-phase tropospheric chemistry of biogenic volatile organic compounds: A review, Atmos. Envrion., 37, S197-S219, 2003.

Bacher, C., Tyndall, G. S., and Orlando, J. J.: The atmospheric chemistry of glycolaldehyde, J. Atmos. Chem., 39, 171-189, 2001.

Baker, B., Guenther, A., Greenberg, J., and Fall, R.: Canopy level fluxes of 2-methyl-3-butene-2-ol, acetone, and methanol by a portable relaxed eddy accumulation system, Environ. Sci. Technol., 35, 1701-1708, 2001. 
Benkovitz, C. M., Schwartz, S. E., Jensen, M. P., Miller, M. A., Easter, R. C., and Bates, T. S.: Modeling atmospheric sulfur over the northern hemisphere during the Aerosol Characterization Experiment 2 experimental period, J. Geophys. Res.Atmos., 109(34), D22207, doi:10.1029/2004jd004939, 2004.

Blake, R. S., Monks, P. S., and Ellis, A. M.: Protontransfer reaction mass spectrometry, Chem. Rev., 109, 861-896, doi:10.1021/cr800364q, 2009.

Bouvier-Brown, N. C., Holzinger, R., Palitzsch, K., and Goldstein, A. H.: Large emissions of sesquiterpenes and methyl chavicol quantified from branch enclosure measurements, Atmos. Environ., 43, 389-401, doi:10.1016/j.atmosenv.2008.08.039, 2009.

Calogirou, A., Jensen, N. R., Nielsen, C. J., Kotzias, D., and Hjorth, J.: Gas-phase reactions of nopinone, 3-isopropenyl6-oxo-heptanal, and 5-methyl-5-vinyltetrahydrofuran-2-ol with $\mathrm{OH}, \mathrm{NO}_{3}$, and ozone, Environ. Sci. Technol., 33, 453-460, 1999.

Carrasco, N., Doussin, J. F., O'Connor, M., Wenger, J. C., PicquetVarrault, B., Durand-Jolibois, R., and Carlier, P.: Simulation chamber studies of the atmospheric oxidation of 2-methyl-3buten-2-ol: Reaction with hydroxyl radicals and ozone under a variety of conditions, J. Atmos. Chem., 56, 33-55, doi:10.1007/s10874-006-9041-y, 2007.

Ciccioli, P., Brancaleoni, E., Frattoni, M., Di Palo, V., Valentini, R., Tirone, G., Seufert, G., Bertin, N., Hansen, U., Csiky, O., Lenz, R., and Sharma, M.: Emission of reactive terpene compounds from orange orchards and their removal by within-canopy processes, J. Geophys. Res.-Atmos., 104, 8077-8094, 1999.

de Gouw, J. and Warneke, C.: Measurements of volatile organic compounds in the earth's atmosphere using proton-transferreaction mass spectrometry, Mass Spectrom. Rev., 26, 223-257, 2007.

Demarcke, M., Amelynck, C., Schoon, N., Dhooghe, F., Van Langenhove, H., and Dewulf, J.: Laboratory studies in support of the detection of sesquiterpenes by proton-transfer-reactionmass-spectrometry, Int. J. Mass Spectrom., 279, 156-162, doi:10.1016/j.ijms.2008.10.023, 2009.

Dhooghe, F., Amelynck, C., Schoon, N., Debie, E., Bultinck, P., and Vanhaecke, F.: A selected ion flow tube study of the reactions of $\mathrm{H}_{3} \mathrm{O}^{+}, \mathrm{NO}^{+}$and $\mathrm{O}_{2}^{+}$with a series of sesquiterpenes, Int. J. Mass Spectrom., 272, 137-148, 2008.

Di Carlo, P., Brune, W. H., Martinez, M., Harder, H., Lesher, R., Ren, X. R., Thornberry, T., Carroll, M. A., Young, V., Shepson, P. B., Riemer, D., Apel, E., and Campbell, C.: Missing OH reactivity in a forest: Evidence for unknown reactive biogenic VOCs, Science, 304, 722-725, 2004.

Duhl, T. R., Helmig, D., and Guenther, A.: Sesquiterpene emissions from vegetation: a review, Biogeosciences, 5, 761-777, 2008, http://www.biogeosciences.net/5/761/2008/.

Fuentes, J. D., Lerdau, M., Atkinson, R., Baldocchi, D., Bottenheim, J. W., Ciccioli, P., Lamb, B., Geron, C., Gu, L., Guenther, A., Sharkey, T. D., and Stockwell, W.: Biogenic hydrocarbons in the atmospheric boundary layer: A review, Bull. Amer. Meteorol. Soc., 81, 1537-1575, 2000.

Goldstein, A. H. and Galbally, I. E.: Known and unexplored organic constituents in the earth's atmosphere, Environ. Sci. Technol., 41, 1514-1521, 2007.

Guenther, A.: The contribution of reactive carbon emissions from vegetation to the carbon balance of terrestrial ecosystems, Chemosphere, 49, 837-844, 2002.
Guenther, A., Hewitt, C. N., Erickson, D. E., Fall, R., Geron, C., Graedel, T., Harley, P., Klinger, L., Lerdau, M., Mckay, M., Pierce, T., Scholes, B., Steinbrecher, R., Tallamraju, R., Taylor, J., and Zimmerman, P. R.: A global-model of natural volatile organic-compound emissions, J. Geophys. Res.-Atmos., 100, 8873-8892, 1995.

Guenther, A., Karl, T., Harley, P., Wiedinmyer, C., Palmer, P. I., and Geron, C.: Estimates of global terrestrial isoprene emissions using MEGAN (Model of Emissions of Gases and Aerosols from Nature), Atmos. Chem. Phys., 6, 3181-3210, 2006, http://www.atmos-chem-phys.net/6/3181/2006/.

Guenther, A. B., Zimmerman, P. R., Harley, P. C., Monson, R. K., and Fall, R.: Isoprene and monoterpene emission rate variability - model evaluations and sensitivity analyses, J. Geophys. Res.Atmos., 98, 12609-12617, 1993.

Harley, P., Fridd-Stroud, V., Greenberg, J., Guenther, A., and Vasconcellos, P.: Emission of 2-methyl-3-buten-2-ol by pines: A potentially large natural source of reactive carbon to the atmosphere, ISI:000076490200026, 25479-25486, 1998.

Harrison, A.: Chemical ionization reagent ion systems, Chemical ionization mass spectrometry, 2 Edn., CRC Press, 71-112, 1992.

Heiden, A. C., Kobel, K., Komenda, M., Koppmann, R., Shao, M., and Wildt, J.: Toluene emissions from plants, Geophys. Res. Lett., 26, 1283-1286, 1999.

Helmig, D., Bocquet, F., Pollmann, J., and Revermann, T.: Analytical techniques for sesquiterpene emission rate studies in vegetation enclosure experiments, Atmos. Environ., 38, 557-572, doi:10.1016/j.atmosenv.2003.10.012, 2004.

Holzinger, R., Lee, A., Paw, K. T., and Goldstein, U. A. H.: Observations of oxidation products above a forest imply biogenic emissions of very reactive compounds, Atmos. Chem. Phys., 5, 67-75, 2005, http://www.atmos-chem-phys.net/5/67/2005/.

IPCC: Climate change 2007-synthesis report, Geneva, Switzerland, 2007.

Jardine, K., Harley, P., Karl, T., Guenther, A., Lerdau, M., and Mak, J. E.: Plant physiological and environmental controls over the exchange of acetaldehyde between forest canopies and the atmosphere, Biogeosciences, 5, 1559-1572, 2008, http://www.biogeosciences.net/5/1559/2008/.

Jordan, A., Haidacher, S., Hanel, G., Hartungen, E., Mark, L., Seehauser, H., Schottkowsky, R., Sulzer, P., and Mark, T. D.: A high resolution and high sensitvity time-of-flight proton-transferreaction mass spectrometer (PTR-ToF-MS), Int. J. Mass Spectrom., 286(2-3), 122-128, 2009.

Kanakidou, M., Seinfeld, J. H., Pandis, S. N., Barnes, I., Dentener, F. J., Facchini, M. C., Van Dingenen, R., Ervens, B., Nenes, A., Nielsen, C. J., Swietlicki, E., Putaud, J. P., Balkanski, Y., Fuzzi, S., Horth, J., Moortgat, G. K., Winterhalter, R., Myhre, C. E. L., Tsigaridis, K., Vignati, E., Stephanou, E. G., and Wilson, J.: Organic aerosol and global climate modelling: a review, Atmos. Chem. Phys., 5, 1053-1123, 2005,

http://www.atmos-chem-phys.net/5/1053/2005/.

Karl, T., Harley, P., Guenther, A., Rasmussen, R., Baker, B., Jardine, K., and Nemitz, E.: The bi-directional exchange of oxygenated VOCs between a loblolly pine (Pinus taeda) plantation and the atmosphere, Atmos. Chem. Phys., 5, 3015-3031, 2005, http://www.atmos-chem-phys.net/5/3015/2005/.

Kesselmeier, J., Bode, K., Hofmann, U., Muller, H., Schafer, L., 
Wolf, A., Ciccioli, P., Brancaleoni, E., Cecinato, A., Frattoni, M., Foster, P., Ferrari, C., Jacob, V., Fugit, J. L., Dutaur, L., Simon, V., and Torres, L.: Emission of short chained organic acids, aldehydes and monoterpenes from quercus ilex 1 . and pinus pinea 1 . in relation to physiological activities, carbon budget and emission algorithms, Atmos. Environ., 31, 119-133, 1997.

Kesselmeier, J., Ciccioli, P., Kuhn, U., Stefani, P., Biesenthal, T., Rottenberger, S., Wolf, A., Vitullo, M., Valentini, R., Nobre, A., Kabat, P., and Andreae, M. O.: Volatile organic compound emissions in relation to plant carbon fixation and the terrestrial carbon budget, Global Biogeochem. Cy., 16(4), 1126, doi:10.1029/2001GB001813, 2002.

Kim, S., Karl, T., Helmig, D., Daly, R., Rasmussen, R., and Guenther, A.: Measurement of atmospheric sesquiterpenes by proton transfer reaction-mass spectrometry (PTR-MS), Atmos. Meas. Tech., 2, 99-112, 2009,

http://www.atmos-meas-tech.net/2/99/2009/.

Kroll, J. H. and Seinfeld, J. H.: Chemistry of secondary organic aerosol: Formation and evolution of low-volatility organics in the atmosphere, Atmos. Environ., 42, 3593-3624, doi:10.1016/j.atmosenv.2008.01.003, 2008.

Kurpius, M. R. and Goldstein, A. H.: Gas-phase chemistry dominates $\mathrm{O}_{3}$ loss to a forest, implying a source of aerosols and hydroxyl radicals to the atmosphere, Geophys. Res. Lett., 30, 1371, doi:10.1029/2002GL016785, 2003.

Lee, A., Goldstein, A. H., Keywood, M. D., Gao, S., Varutbangkul, V., Bahreini, R., Ng, N. L., Flagan, R. C., and Seinfeld, J. H.: Gas-phase products and secondary aerosol yields from the ozonolysis of ten different terpenes, J. Geophys. Res.-Atmos., 111, D07302, doi:10.1029/2005JD006437, 2006.

Lee, A., Schade, G. W., Holzinger, R., and Goldstein, A. H.: A comparison of new measurements of total monoterpene flux with improved measurements of speciated monoterpene flux, Atmos. Chem. Phys., 5, 505-513, 2005,

http://www.atmos-chem-phys.net/5/505/2005/.

Mielke, L. H., Erickson, D. E., McLuckey, S. A., Muller, M., Wisthaler, A., Hansel, A., and Shepson, P. B.: Development of a proton-transfer reaction-linear ion trap mass spectrometer for quantitative determination of volatile organic compounds, Anal. Chem., 80, 8171-8177, doi:10.1021/ac801328d, 2008.

Ng, N. L., Kroll, J. H., Keywood, M. D., Bahreini, R., Varutbangkul, V., Flagan, R. C., Seinfeld, J. H., Lee, A., and Goldstein, A. H.: Contribution of first- versus second-generation products to secondary organic aerosols formed in the oxidation of biogenic hydrocarbons, Environ. Sci. Technol., 40, 2283-2297, doi:10.1021/es052269u, 2006.

Orlando, J. J., Noziere, B., Tyndall, G. S., Orzechowska, G. E., Paulson, S. E., and Rudich, Y.: Product studies of the $\mathrm{OH}-$ and ozone-initiated oxidation of some monoterpenes, J. Geophys. Res.-Atmos., 105, 11561-11572, 2000.

Ortega, J., Helmig, D., Daly, R. W., Tanner, D. M., Guenther, A. B., and Herrick, J. D.: Approaches for quantifying reactive and low-volatility biogenic organic compound emissions by vegetation enclosure techniques - part b: Applications, Chemosphere, 72, 365-380, doi:10.1016/j.chemosphere.2008.02.054, 2008.

Ruuskanen, T. M., Hakola, H., Kajos, M. K., Hellen, H., Tarvainen, V., and Rinne, J.: Volatile organic compound emissions from Siberian Larch, Atmos. Environ., 41, 5807-5812, doi:10.1016/j.atmosenv.2007.05.036, 2007.
Ryerson, T. B., Trainer, M., Holloway, J. S., Parrish, D. D., Huey, L. G., Sueper, D. T., Frost, G. J., Donnelly, S. G., Schauffler, S., Atlas, E. L., Kuster, W. C., Goldan, P. D., Hubler, G., Meagher, J. F., and Fehsenfeld, F. C.: Observations of ozone formation in power plant plumes and implications for ozone control strategies, Science, 292, 719-723, 2001.

Sakulyanontvittaya, T., Guenther, A., Helmig, D., Milford, J., and Wiedinmyer, C.: Secondary organic aerosol from sesquiterpene and monoterpene emissions in the United States, Environ. Sci. Technol., 42, 8784-8791, 2008.

Schade, G. W. and Goldstein, A. H.: Fluxes of oxygenated volatile organic compounds from a ponderosa pine plantation, J. Geophys. Res.-Atmos., 106, 3111-3123, 2001.

Schoon, N., Amelynck, C., Vereecken, L., Coeckelberghs, H., and Arijs, E.: A selected ion flow tube study of the reactions of $\mathrm{H}_{3} \mathrm{O}^{+}, \mathrm{NO}^{+}$and $\mathrm{O}_{2}^{+}$with some monoterpene oxidation products, International J. Mass Spectrom., 239, 7-16, doi:10.1016/j.ijms.2004.09.003, 2004.

Shetter, R. E., Davidson, J. A., Cantrell, C. A., and Calvert, J. G.: Temperature variable long path cell for absorptionmeasurements, Rev. Sci. Instrum., 58, 1427-1428, 1987.

Taipale, R., Ruuskanen, T. M., Rinne, J., Kajos, M. K., Hakola, H., Pohja, T., and Kulmala, M.: Technical Note: Quantitative long-term measurements of VOC concentrations by PTR-MS measurement, calibration, and volume mixing ratio calculation methods, Atmos. Chem. Phys., 8, 6681-6698, 2008, http://www.atmos-chem-phys.net/8/6681/2008/.

Tani, A., Hayward, S., Hansel, A., and Hewitt, C. N.: Effect of water vapour pressure on monoterpene measurements using proton transfer reaction-mass spectrometry (PTR-MS), Int. J. Mass Spectrom., 239, 161-169, 2004.

Tani, A., Hayward, S., and Hewitt, C. N.: Measurement of monoterpenes and related compounds by proton transfer reaction-mass spectrometry (PTR-MS), Int. J. Mass Spectrom., 223, 561-578, 2003.

Vuorinen, T., Nerg, A. M., Vapaavuori, E., and Holopainen, J. K.: Emission of volatile organic compounds from two silver birch (betula pendula roth) clones grown under ambient and elevated $\mathrm{CO}_{2}$ and different $\mathrm{O}_{3}$ concentrations, Atmos. Environ., 39, 1185-1197, doi:10.1016/j.atmosenv.2004.09.077, 2005.

White, M. L., Russo, R. S., Zhou, Y., Ambrose, J. L., Haase, K., Frinak, E. K., Varner, R. K., Wingenter, O. W., Mao, H., Talbot, R., and Sive, B. C.: Are biogenic emissions a significant source of summertime atmospheric toluene in the rural Northeastern United States?, Atmos. Chem. Phys., 9, 81-92, 2009, http://www.atmos-chem-phys.net/9/81/2009/.

Wiedinmyer, C., Guenther, A., Harley, P., Hewitt, N., Geron, C., Artaxo, P., Steinbrecher, R., and Rasmussen, R.: Global organic emissions from vegetation, in: Emissions of atmospheric trace compounds, edited by: Granier, C., Artaxo, P., and Reeves, C., Kluwer Academic Publishers, 115-170, 2004.

Wisthaler, A., Jensen, N. R., Winterhalter, R., Lindinger, W., and Hjorth, J.: Measurements of acetone and other gas phase product yields from the $\mathrm{OH}$-initiated oxidation of terpenes by protontransfer-reaction mass spectrometry (PTR-MS), Atmos. Environ., 35, 6181-6191, 2001.

Zhao, J., Zhang, R. Y., Fortner, E. C., and North, S. W.: Quantification of hydroxycarbonyls from oh-isoprene reactions, J. Am. Chem. Soc., 126, 2686-2687, doi:10.1021/ja0386391, 2004. 